Original Research Article

\title{
An observational comparative study of different doses of azilsartan and with chlorthalidone combination in moderate hypertension
}

\author{
Tamoghna Maiti ${ }^{1}$, Sonai Mandal ${ }^{1 *}$, Ratul Banerjee ${ }^{1}$, Sourav Chakrabarty $^{2}$, Amrita Panda $^{3}$
}

\author{
${ }^{1}$ Department of Pharmacology, \\ Bankura Sammilani Medical \\ College and Hospital, Bankura, \\ West Bengal, India \\ ${ }^{2}$ Department of Pharmacology, \\ Purila Govt. Medical College \\ and Hospital, Purulia, West \\ Bengal, India \\ ${ }^{3}$ Anthropological Survey of \\ India, Kolkata, West Bengal, \\ India
}

Received: 27 November 2018

Revised: 28 December 2018

Accepted: 03 January 2019

*Correspondence to:

Dr. Sonai Mandal,

Email: manadal.sonai@ yahoo.co.in

Copyright: (C) the author(s), publisher and licensee Medip Academy. This is an openaccess article distributed under the terms of the Creative Commons Attribution NonCommercial License, which permits unrestricted noncommercial use, distribution, and reproduction in any medium, provided the original work is properly cited.

\begin{abstract}
Background: High blood pressure (BP) is one of the significant noncommunicable diseases that are of high prevalence in our country. Hypertension (HTN) is responsible cause of $57 \%$ of stroke and $24 \%$ of coronary heart disease deaths in India. Eight classes of medications are currently used in the treatment of hypertension. Azilsartan medoxomil is a newly added FDA approved drug to the ARB class of antihypertensive agents. azilsartan and chlorthalidone combination is also got the FDA approval. There is limited study in between these two groups regarding efficacy especially in rural Bengal.

Methods: A prospective observational study was done in medicine OPD of Bankura Sammilani Medical College for twelve weeks with two groups that are azilsartan (80mg) and fixed dose combination of azilsartan (40mg) plus chlorthalidone (12.5mg) in the age group of 18 to 55years of moderate hypertensive patients. Change of heart rate was assessed as safety parameter.

Results: It was found that both the group of drugs are very much effective in lowering blood pressure constantly in respect of both systolic and diastolic BP but azilsartan monotherapy in high dose reduce systolic blood pressure slightly high. Significant change of heart rate was not seen with both the groups.

Conclusions: Both the group was effective as well as safe in hypertensive patients.
\end{abstract}

Keywords: Azilsartan, Blood pressure, Chlorthalidone, Heart rate

\section{INTRODUCTION}

Hypertension (HTN) exerts a substantial public health burden on cardiovascular health status and is worrisome problem of our healthcare system. Hypertension (HTN) is responsible cause of $57 \%$ of stroke and $24 \%$ of coronary heart disease deaths in India. ${ }^{1}$ The prevalence of hypertension in Indian cities has been steadily increasing from $3.0-4.5 \%$ in early 1960 's to 11.0 to $15.5 \%$ in mid$1990{ }^{\prime}$ s. $^{2}$ Although rural populations in India generally have lower prevalence of hypertension there has been a significant increase in these populations from less than $1 \%$ in early 1960 's to $5-7 \%$ in late 1990 's. $^{2}$ An alarming rise in HTN projected by Global Burden of Hypertension 2005 study, the GBD 2010 study and WHO 2011 NCD India specific data portrays a grim picture for the $17.8 \%$ of the world's population who reside in India. ${ }^{3-5}$ One of the goals of antihypertensive therapy is to bring the overall mean BP down, but also to reduce the daily variability. Eight classes of medications are currently used in the treatment of 
hypertension. They include diuretics, angiotensinconverting enzyme (ACE) inhibitors, angiotensin II receptor blockers (ARB), calcium-channel blockers (CCB), beta-adrenergic blockers, alpha-adrenergic blockers central alpha-adrenergic receptor agonists and direct renin inhibitors (DRIs). Many of these drugs are available in combination with other antihypertensive agents, such as the aliskiren, the CCB amlodipine, and the thiazide diuretics. The goal for maintaining $\mathrm{BP}$ is $<130 / 90 \mathrm{~mm}$ of $\mathrm{Hg}$ according to recent guidelines. According to JNC -8 guideline the four groups ACE, ARB, $\mathrm{CCB}$, Thiazide are the initial choice should be unless and otherwise any contraindication or compelling indication is present.

Azilsartan medoxomil is a newly added to the ARB class of antihypertensive agents. It received FDA approval in February 2011. Azilsartan and chlorthalidone combination got the same in December 2011. Angiotensin II, a peptide hormone, is the principal pressor agent of the reninangiotensin system (RAS). It is also a potent, direct vasoconstrictor. It stimulates the synthesis and release of aldosterone and thus promotes renal tubular reabsorption of sodium and causes sodium and water retention. As an ARB, azilsartan medoxomil selectively inhibits angiotensin II from binding to the angiotensin II type-1 receptor (AT1). By blocking the action of angiotensin II, azilsartan exerts its antihypertensive effect.

Azilsartan medoxomil is a prodrug, which is hydrolized to its active moiety, azilsartan, at the level of the gastrointestinal tract. Azilsartan reaches its peak plasma concentration between 1.5 and 3 hours after administered orally. If it is administered with food, that does not affect its bioavailability, which is approximately $58 \%{ }^{6}$ Azilsartan is metabolized in the liver (by O-dealkylation) via cytochrome $\mathrm{P} 450$ (CYP) 2C9, resulting in the formation of a nonactive metabolite, M-II.

Serum concentrations of chlorthalidone reaches its peak at approximately 2-6 hours., ${ }^{7,8}$ The recommended starting dose of azilsartan/chlorthalidone is $40 / 12.5 \mathrm{mg}$ taken orally once daily. Most of the antihypertensive effect is apparent within 1 to 2 weeks. The recommended starting dose of azilsartan is $80 \mathrm{mg}$. Azilsartan is a safe and effective treatment option for every stage of hypertension, both alone or in fixed-dose combination tablets with chlorthalidone or amlodipine. ${ }^{9}$

\section{METHODS}

It was a prospective observational study. The study was done in medicine Out Patient Department of , Bankura Sammilani Medical College \& Hospital, Bankura, West Bengal in rural Bengal for the period of three month from the month of February to month of April in the year 2018. the patients were examined at the starting of therapy, then after 2 weeks, 4 weeks, 8 weeks and 12 weeks respectively for blood pressure and heart rate.

\section{Inclusion criteria}

- Patients greater than18years and less than 55years of age

- Patients of either sex of above criteria.

- Drug naïve patient.

- Patient noncompliance on ACE inhibitor due to adverse reaction

- Patient was on mono-therapy with either ARB or Thiazide and not controlling.

\section{Exclusion criteria}

- Patient of <18year and >55year

- Patient was on any antihypertensive mono-therapy other than ARB

- Patient was on combination therapy

- Any comorbid condition

- Pregnant and lactating woman

- Any history of drug allergy of ARB.

Clinic blood pressure (BP) was measured by the physician according to guidelines of the International Society of Hypertension (ISH)/World Health Organisation (WHO) 1999 and the JNC-7. ${ }^{10}$ Measurements were taken using a standard mercury sphygmomanometer with appropriate cuff size. Three BP measurements were taken using the subject's right arm with the subject in the sitting position after five minutes of rest, with one minute between measurements. The mean of three measurements were taken as the final value.

Participants with an elevated BP measurement were advised to attend a second visit after one week for measuring their BP again. The average BP of the second visit was used as a criterion for the diagnosis and control of hypertension.

In addition, all treated hypertensive patients were asked to return for a second visit after two weeks and then again as stated above to have their BP measured. Hypertension was defined as systolic blood pressure (SBP) $\geq 140 \mathrm{mmHg}$, diastolic blood pressure (DBP) $\leq 90 \mathrm{~mm} \mathrm{Hg}$. Then the medicines were given by physician of his choice in two groups azilsartan (80mg) -group 1 and azilsartan 80mg+ chlorthalidone $12.5 \mathrm{mg}$-group 2 and the data were putted in a case reporting form after every check-up. Recruitment done on the basis of inclusion and exclusion criteria and the recruitment procedure was done for first three months. Each patient was observed for a period for three months. They were checked on $2^{\text {nd }}, 4^{\text {th }}, 8^{\text {th }}$ and $12^{\text {th }}$ week.

Then BP of every check-up were distributed in a XL spread-shit and then analysed by using a Graph-pad prism version 6 software and also SPSS 22 software and ultimately concluded as the lowering of blood pressure in each group. Unpaired $\mathrm{t}$ test and Friedman one way ANOVA were used as statistical test. The baseline BP were also analysed. 


\section{RESULTS}

The results were obtained by using Graph pad prism and SPSS 22 software and analysed.

Authors found that in azilsartan 80mg group (group 1), mean age was 58.38 year with standard deviation (SD) 13.95 and in azilsartan $40 \mathrm{mg}$ plus chlorthalidone $12.5 \mathrm{mg}$ group (group 2), mean age was 53.58year and SD was 11.5. In case of height we found mean and SD $165.79 \mathrm{~cm}$ and 9.08 in group 1 and $161.58 \mathrm{~cm}$ and $11.95 \mathrm{~cm}$ in group 2. In case of weight we found in group 1 mean $75.62 \mathrm{~kg}$ and SD 10.88 and group 2 mean $66.26 \mathrm{~kg}$ and SD 11.23. In case of age, height and weight $P$ value was $0.639,0.094$ and 0.829 respectively, those were insignificant. In case of sex distribution, authors found significant $\mathrm{P}$ value of 0.045 which clearly shows male preponderance of hypertension (Figure 1).

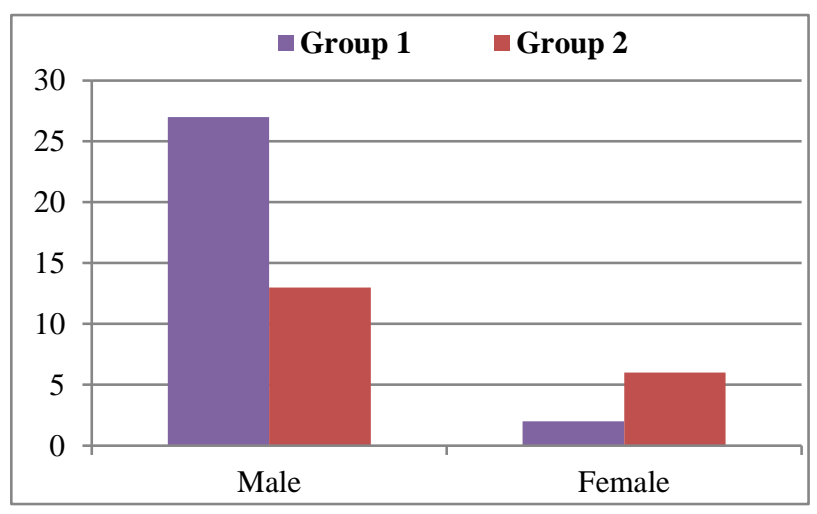

Figure 1: Sex distribution.

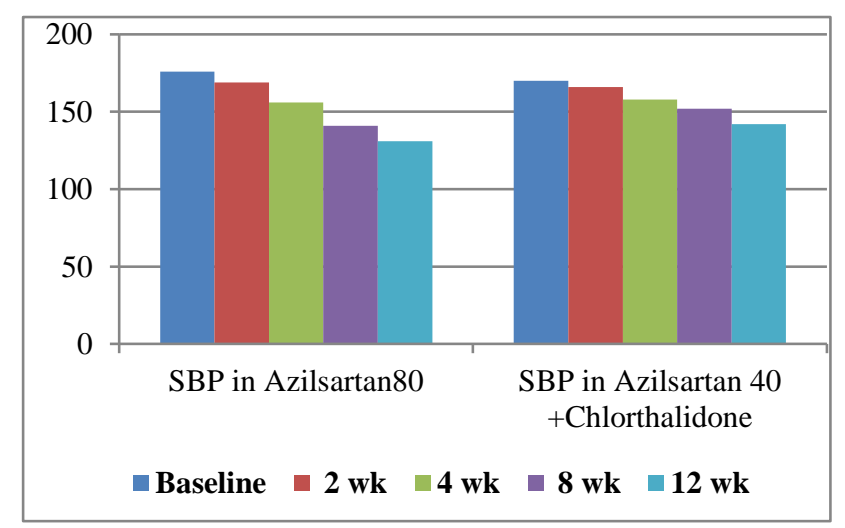

Figure 2: SBP changes in two groups.

Authors analyse the base line systolic (SBP) and diastolic blood pressure (DBP) in two group to see whether there any significance difference or not and found $p$ value 0.0877 in SBP and 0.0612 in DBP, non-significant in both the occasion. The patients were again checked for blood pressure on $2 \mathrm{wk}, 4 \mathrm{wk}, 8 \mathrm{wk}, 12 \mathrm{wk}$ and recorded. Authors found in group 1 the significant fall in SBP and also in DBP. In both occasion it was found $<0.0001$, that is highly sensitive. In case of SBP in group 1 differences between all observations from baseline to 1 st visit and consequently in all the next visits. The mean value was 175.9, 169.2, 155.6, 141.0 and 131.2 subsequently (Figure 2 ).

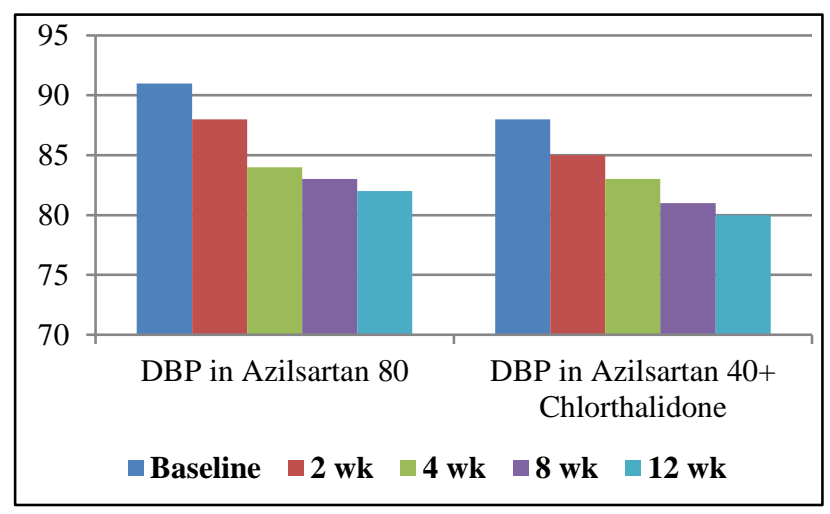

Figure 3: DBP changes in two groups.

Mean value in case of SBP change was9.84, 10.08, 9.86, $8.69,7.84$ in respective visit. In case of DBP of group 1 the mean value was 90.55, 87.59, 84.00, 82.83, 81.17 (Figure 3) and SD was 4.72, 4.42, 4.17, 3.32, 2.80 respectively. So, it is clearly efficacious in reducing both SBP and DBP.

In case of group 2 the $p$ value was insignificant in SBP in first visit and then these were significant $<0.001$ in all occasions but in case of DBP $\mathrm{p}$ value was significant $<0.001$ in all cases. In case of SBP the mean were 170.42 , 165.63, 158.21, 151.28, 142.00 (Figure 2) and SD WERE $11.92,11.77,10.11,9.15,4.57$ in respective visits. In case of DBP the value of mean and SD were 87.79, 85.16, 82.63, $81.05,80.00$ (Figure 3) and 5.12, 6.48, 4.67, 4.78, 3.27. So azilsartan $40 \mathrm{mg}$ and chlorthalidone $12.5 \mathrm{mg}$ combination is also effective in reducing blood pressure systolic as well as diastolic.

If authors consider in between two group then in case of SBP no significant difference in first two visits but significantly fall in SBP after 8week and 12 weeks in case of azilsartan $80 \mathrm{mg}$ than azilsartan $40 \mathrm{mg}$ and chlorthalidone $12.5 \mathrm{mg}$, $\mathrm{p}$ value 0.0002 in $8 \mathrm{wk}$ and $<0.0001$ in $12 \mathrm{wk}$. The mean value in group2 and group 1 was 151.48 and 141.03 respectively at 8 week and 142 and 131.17 respectively at 12 week. The SD value in group 1 and group 2 was 9.15 and 8.69 at 8 week and 4.57 and 7.84 at 12 weeks.

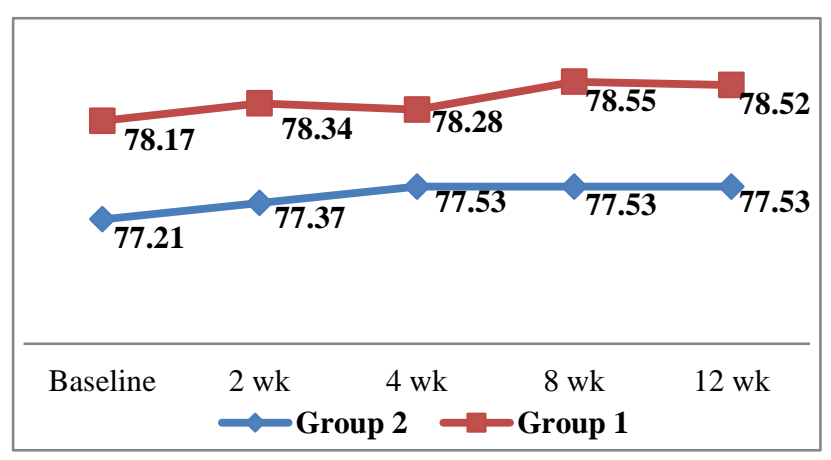

Figure 4: Heart rate changes group-wise and in follow-up. 
Heart rates were also observed in two groups for safety parameter. Authors found that heart rate change was insignificant in $p$ value 0.238 in group 1 , but $p$ value is significant 0.017 in case of group 2 . When we search for detail into these variations, we found $\mathrm{p}$ value in group 2 significant from baseline to $4 \mathrm{wk}, 8 \mathrm{wk}$ and $12 \mathrm{wk}$. But the mean was 77.21 at baseline and then $77.37,77.53,77.53$ and 77.53 in subsequent visits (Figure 4). These all are insignificant clinically.

So, both the group are safe in respect of heart rate.

\section{DISCUSSION}

It is recommended that for many hypertensive patients requiring a $>20 \mathrm{mmHg}$ decrease in SBP need combined therapy. ${ }^{10}$ In the ALLHAT trial, authors have seen $63 \%$ of the study population was given two or more drugs; and at the end of 5 years only $66 \%$ had achieved controlled BP. ${ }^{11}$ It is obvious with some newer trials that high rates of patients requiring more than one drug for BP management; example- INVEST (80\%), ASCOT-BPLA (78\%), and LIFE $(88 \%) .{ }^{12-14}$ In present country many patient needed combination drug for controlling high blood pressure and it is very effective to combine drugs to start treatment.

The benefits of combination therapy compared to monotherapy include increased BP control by different mechanisms of action, lowering dose requirements, and fewer adverse events.

Authors have a very small study population and in rural Bengal where patient compliance is a very big issue, authors have found the result a little bit different in current study.

If authors consider in between two group then in case of Systolic BP, no significant difference in first two visits but significantly fall in SBP after 8week and 12week in case of azilsartan $80 \mathrm{mg}$ than azilsartan $40 \mathrm{mg}$ and chlorthalidone $12.5 \mathrm{mg}$. The mean value in group 2 and group 1 was 151.48 and 141.03 respectively at 8 week and 142 and 131.17 respectively at12 weeks. That we found a greater achievement in azilsartan monotherapy with $80 \mathrm{mg}$ dose in last two visits. But both the group of drugs is very much effective in lowering blood pressure constantly in respect of both systolic and diastolic BP. Authors have also studied if any change of heart rate is occurring and we found that no clinically significant change occurs over the 3 months study period in heart rate in our study.

\section{ACKNOWLEDGEMENTS}

Authors would like to thank to Dr. Shyamal Kundu, H.O.D. Department of medicine, and Dr. S.M. Naser, H.OD. Department of Pharmacology and also to Associate Professor Dr. Ananya Mandal and Assistant Professor Dr. Tanmoy Gangopadhyay for their co-operation in present work and also grateful to all non-medical staffs of Medicine OPD and Pharmacology Department of Bankura
Sammilani Medical College for their help in present work. Authors are also thankful to all PGTs and other faculty of Pharmacology Department of the same institution.

Funding: No funding sources

Conflict of interest: None declared

Ethical approval: The study was approved by the Institutional Ethics Committee

\section{REFERENCES}

1. Gupta R. Trends in hypertension epidemiology in India. J Human Hypertension. 2004 Jan 5;18(2):73.

2. Gupta R, Gupta S. Hypertension in India: Trends in prevalence, awareness, treatment and control. RUHS J Health Sci. 2017;2(1):40-6.

3. Kearney PM, Whelton M, Reynolds K, Muntner P, Whelton PK, He J. Global burden of hypertension: analysis of worldwide data. Lancet. 2005 Jan 15;365(9455):217-23.

4. Lim SS, Vos T, Flaxman AD, Danaei G, Shibuya K, Adair-Rohani H, et al. A comparative risk assessment of burden of disease and injury attributable to 67 risk factors and risk factor clusters in 21 regions, 19902010: a systematic analysis for the Global Burden of Disease Study 2010. Lancet. 2012 Dec 15;380(9859):2224-60.

5. Noncommunicable diseases country profiles 2011. Available http://www.who.int/nmh/countries/ind_en.pdf Accessed 10 May 2013.

6. Edarbi® (prescribing information) Deerfield, IL: Takeda Pharmaceuticals America, Inc; 2012. Available at: http://www.edarbi.com/. Accessed 22 February, 2016.

7. Cheng JW. Azilsartan/chlorthalidone combination therapy for blood pressure control. Integrated Blood Pressure Control. 2013;6:39-48.

8. McAinsh J, Bastain W, Young J, Harry JD. Bioavailability in man of atenolol and chlorthalidone from a combination formulation. Biopharmaceut Drug Disposition. 1981 Apr;2(2):147-56.

9. Khan MA, Neckář J, Cummens B, Wahl GM, Imig JD. Azilsartan decreases renal and cardiovascular injury in the spontaneously hypertensive obese rat. Cardiovasc Drugs Therapy. 2014 Aug 1;28(4):313-22.

10. Chobanian AV, Bakris GL, Black HR, Cushman WC, Green LA, Izzo JL Jr, et al. The seventh report of the joint national committee on prevention, detection, evaluation, and treatment of high blood pressure: the JNC 7 report. JAMA. 2003 May 21;289(19):2560-72.

11. Cushman WC, Ford CE, Cutler JA, Margolis KL, Davis BR, Grimm RH, et al. Original Papers. Success and predictors of blood pressure control in diverse north american settings: The Antihypertensive and Lipid-Lowering Treatment to Prevent Heart Attack Trial (ALLHAT). J Clin Hypertension. 2002 Nov;4(6):393-404.

12. Dahlöf B, Devereux RB, Kjeldsen SE, Julius S, Beevers G, de Faire U, et al. Cardiovascular morbidity 
and mortality in the losartan intervention for endpoint reduction in hypertension study (LIFE): a randomised trial against atenolol. Lancet. 2002 Mar 23;359(9311):995-1003.

13. Pepine CJ, Handberg EM, Cooper-DeHoff RM, Marks RG, Kowey P, Messerli FH, et al. A calcium antagonist vs a non-calcium antagonist hypertension treatment strategy for patients with coronary artery disease: the International Verapamil-Trandolapril Study (INVEST): a randomized controlled trial. JAMA. 2003 Dec 3;290(21):2805-16.

14. Dahlöf B, Sever PS, Poulter NR, Wedel H, Beevers DG, Caulfield M, et al. Prevention of cardiovascular events with an antihypertensive regimen of amlodipine adding perindopril as required versus atenolol adding bendroflumethiazide as required, in the Anglo-Scandinavian Cardiac Outcomes TrialBlood Pressure Lowering Arm (ASCOT-BPLA): a multicentre randomised controlled trial. Lancet. 2005 Sep 10;366(9489):895-906.

Cite this article as: Maiti T, Mandal S, Banerjee R, Chakrabarty S, Panda A. An observational comparative study of different doses of azilsartan and with chlorthalidone combination in moderate hypertension. Int J Basic Clin Pharmacol 2019;8:259-63. 